\title{
A clinico-pathological study of patients with thyroid swelling and their management in a tertiary care centre in western Uttar Pradesh
}

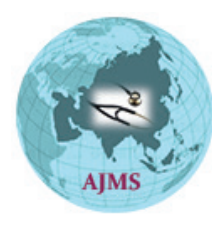

\author{
Mohini Tyagi', Probal Chatterji² \\ ${ }^{1}$ Post Graduate Trainee, ${ }^{2}$ Professor \& Head, Department of Otorhinolaryngology \& Head-Neck Surgery, Teerthanker \\ Mahaveer Medical College \& Research Center, Moradabad, Uttar Pradesh - 244001, India
}

Background: Thyroid diseases are common worldwide and in India too there is a significant burden of thyroid disease. Thyroid disease has a reported prevalence of $4-7 \%$ in the general population on neck palpation and in autopsy series it may be as high as $50 \%$ if subclinical nodules are included. The clinical presentation of thyroid swellings can be very misleading and a definitive diagnosis cannot be done without proper investigations. Aims: To conduct a clinicpathological study of thyroid swellings along with their management in a tertiary care center. Objectives: 1 . To study the various clinical presentations of thyroid swellings 2 . To record the FNAC findings in each case. 3. To perform histopathological examination of all operative specimens and compare the results with preoperative diagnosis. Materials and Methods: A one-year prospective study was done in which 50 patients with thyroid swelling were identified. Detailed information regarding all relevant parameters was recorded and treatment was done as per standard protocol. Results: Female preponderance of cases was seen (3.16:1). Maximum cases were in $36-45$ year age group and $70 \%$ cases were premenopausal females. Multinodular goiter was commonest clinical presentation and colloid goiter was most common FNAC finding. Hemithyroidectomy was the most frequently performed operation. Final results showed that colloid goiter was the most commonly diagnosed benign condition while papillary carcinoma was the commonest malignancy. Conclusion: Most studies show female preponderance of cases. Multinodular goiter is the commonest clinical presentation world-wide. Colloid goiter is the most commonly diagnosed cause of thyroid swelling. Though FNAC is not $100 \%$ accurate, it has an important role in the initial evaluation of these patients. Histopathogical examination of specimen is the gold-standard investigation for final diagnosis. Due to the risk of an underlying malignancy, a proper evaluation of thyroid swellings is a must as they have excellent cure rate if treated early.

Key words: Colloid goiter; Multinodular goiter; Solitary Thyroid nodule; Thyroid neoplasm
Access this article online

\section{Website:}

http://nepjol.info/index.php/AJMS

DOI: 10.3126/ajms.v12i1.31078

E-ISSN: 2091-0576

P-ISSN: 2467-9100

Copyright (c) 2021 Asian Journal of Medical Sciences

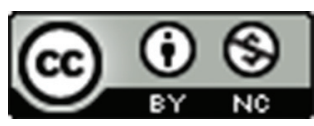

This work is licensed under a Creative Commons Attribution-NonCommercial 4.0 International License.

\section{INTRODUCTION}

The most common presentation of thyroid disease is 'thyroid swelling'. It may present as a nodule (single or multiple), generalised diffuse swelling or with grossly altered gland architecture (as in multinodular goitre) along with normal or deranged serum thyroid profile. ${ }^{1}$ Thyroid diseases are common worldwide and in India too there is a significant burden of thyroid disease. It has been estimated that thyroid disease has a reported prevalence of $4 \%$ to
$7 \%$ in the general population on neck palpation. ${ }^{2}$ However, very small nodules and subclinical pathologies may easily be missed and the prevalence of nodules in autopsy series is much higher and approaches $50 \%{ }^{3}$ Some authors have suggested that in absolute numbers, about 42 million people in India suffer from thyroid diseases. ${ }^{4}$

The clinical presentation of thyroid swellings can be very misleading and a definitive diagnosis cannot be done without proper investigations. The role of Fine Needle 
Aspiration Cytology (FNAC) cannot be over emphasised because the treatment protocol is entirely dependent on the pathological findings. Even though most thyroid disorders are benign, $5-20 \%$ of thyroid swellings may also have underlying carcinomas. These cases need to be identified promptly as treatment results of thyroid malignancies are extremely good if early management is initiated. ${ }^{5}$

Due to the unique location of our hospital, we receive patients from both the plains as well as the sub-Himalayan region where iodine deficiency is one of the major causes of high prevalence of goitre. ${ }^{6}$ Thus we performed the present study with the following aims and objectives.

Aims: To conduct a clinic-pathological study of thyroid swellings along with their management in a tertiary care center.

Objectives: 1 . To study the various clinical presentations of thyroid swellings 2. To record the FNAC findings in each case along with other necessary investigations. 3. To perform histopathological examination of all operative specimens and compare the results with preoperative diagnosis.

\section{MATERIAL AND METHODS}

A prospective observational study was done at Teerthanker Mahaveer Medical College \& Hospital, Moradabad from November 2018 to October 2019. The patients were chosen from those presenting with thyroid swelling in the ENT outpatient department. Fifty patients were identified during a study period

\section{Inclusion criteria}

- All patients presenting with thyroid swelling.

- Voluntary participation in the study

\section{Exclusion criteria}

- When surgical intervention was indicated but not possible (due to other co-morbidities) and definitive diagnosis could not be reached.

- Patients lost to follow up.

After proper consent, a detailed history was taken regarding the relevant points in every case followed by detailed otolaryngological and neck examination. All the data was recorded in a case sheet specially prepared for this purpose.

Every patient was investigated as follows:

- USG of neck

- Serum thyroid profile (TSH, free T3 \&T4)

- FNAC from swelling

- CT scan of neck (when specifically indicated).
- Histopathological examination of surgical specimen (where applicable)

Patients diagnosed with medical conditions were managed medically and those diagnosed with surgically treatable conditions were operated after obtaining surgical consent and proper pre-operative check up.

Finally, histopathological report of the surgical specimen was obtained where applicable and correlated with preoperative FNAC report. All findings were recorded.

\section{RESULTS}

A total of 50 subjects with thyroid swelling were identified in our study. Out of them, 38 were females and 12 were males. Thus, females far outnumbered males in a ratio of 3.16:1.

Most common age group in which thyroid swelling was identified was $36-45$ years ( $42 \%$ ) followed by $26-35$ years age group (30\%). In other words, $72 \%$ patients were in the age group of 26-45 years of age. Least number of patients was in 56-65 years age group (4\%) and none were identified below the age of 16 years or above 65 year of age.

Further analysis reveals that $70 \%$ cases (35 cases) were females in the pre-menopausal age group of 16-45 years. Only 3 females in our study were outside this age group in the post-menopausal age. The detailed age and sex distribution of patients is shown in Figure 1.

Clinically most swellings presented as multinodular goiter $(60 \%)$ followed by solitary thyroid nodule in $(34 \%)$ and diffuse goiter $(6 \%)$.

On evaluation by FNAC, the most common diagnosis was colloid goiter in $82 \%$ cases, followed by other pathologies making up the rest as shown in the Table 1.

One case of colloid goiter was evaluated and diagnosed as a case of puberty goiter. This along with 3 cases of Hashimoto's thyroiditis was managed medically. The rest 46 cases were operated after obtaining GA fitness.

\begin{tabular}{lcc}
$\begin{array}{l}\text { Table 1: Fine needle aspiration cytology (FNAC) } \\
\text { findings }\end{array}$ & Frequency & Percent \\
\hline FNAC Report & 41 & $82 \%$ \\
\hline Colloid goiter & 3 & $6 \%$ \\
Hashimoto's Thyroiditis & 1 & $2 \%$ \\
Langerhans cell Histiocytosis & 2 & $4 \%$ \\
Follicular Neoplasm & 3 & $6 \%$ \\
Papillary Carcinoma & 50 & $100 \%$ \\
Total &
\end{tabular}

Asian Journal of Medical Sciences | Jan 2021 | Vol 12 | Issue 1 


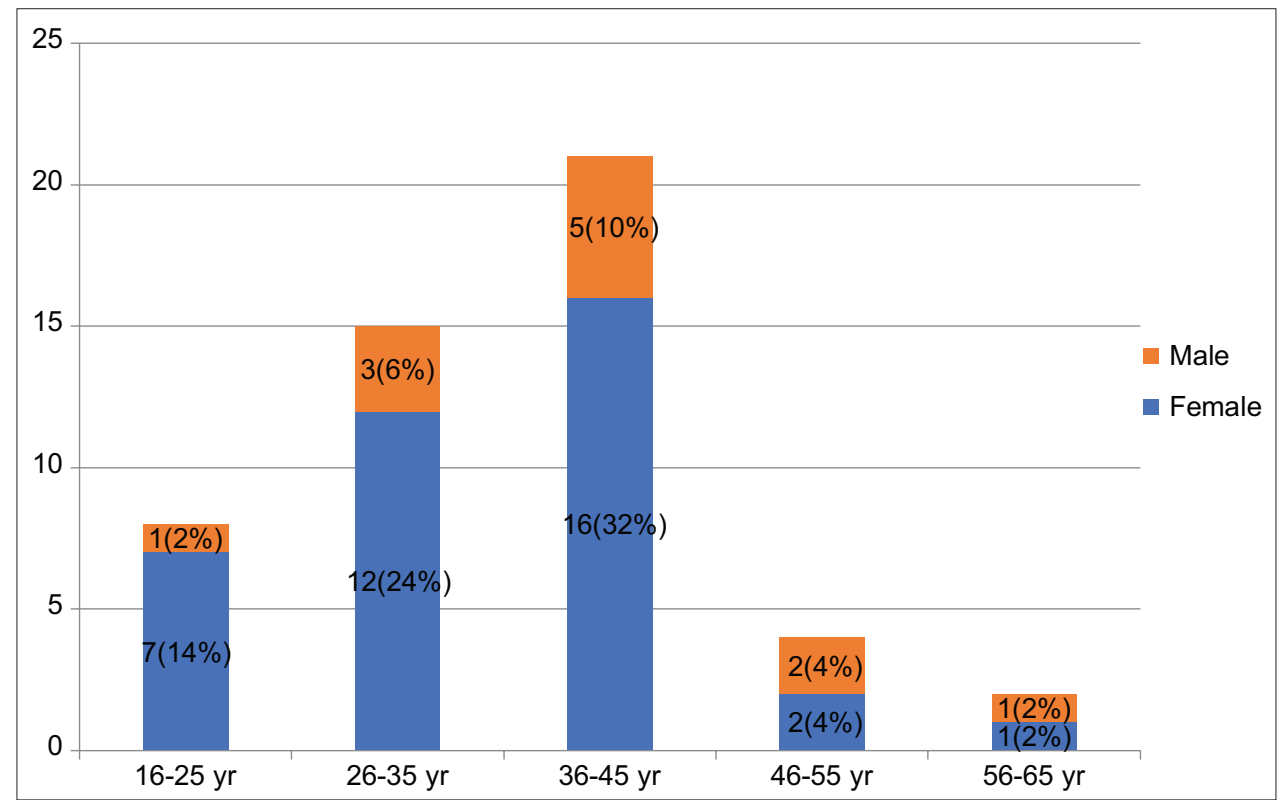

Figure 1: Age and sex distribution of patients

Analysis of thyroid profile of the patients revealed that 45 cases were euthyroid. A total of 4 patients had features of hypothyroidism. Of them, 2 were patients of Hashimoto's thyroiditis and were managed medically. Two cases were colloid goiters and had to be given thyroid hormone supplementation for obtaining euthyroid status before surgery. The single case of colloid goiter with features suggestive of hyperthyroidism was also managed medically with anti-thyroid drugs prior to surgery.

Hemithyroidectomy was the most commonly performed operation in 31 cases $(67.4 \%)$ followed by subtotal thyroidectomy and total thyroidectomy in 5 cases each (10.8\% each), near total thyroidectomy in 3 cases $(6.5 \%)$ and isthmusectomy in 2 cases $(4.3 \%)$.

Analysis of the histopathological reports of the 46 operated cases showed that 2 cases which had been pre-operatively diagnosed as colloid goiter, came out to be papillary CA. Furthermore, out of 2 suspicious cases of follicular neoplasm, one came out to be follicular adenoma and other was diagnosed as follicular carcinoma.

Final diagnosis of the 50 cases in our study showed that $86 \%$ cases had non-neoplastic lesions with colloid goitre being most common comprising $76 \%$ cases. $14 \%$ of total cases consisted of thyroid neoplasms of which papillary carcinoma was most common (10\%) followed by 1 case each ( $2 \%$ each) of follicular adenoma and follicular carcinoma.

The final diagnosis of all cases is shown in Table 2.

\section{DISCUSSION}

In our study, there was strong female preponderance of cases. We encountered 38 females $(76 \%)$ and 12 males $(24 \%)$ in a ratio of $3.16: 1$. Most studies corroborate the same findings. Jawaid et al also found thyroid disorder to be more predominant in females. ${ }^{3}$ In another large case series published in 2005, the study population consisted of 339 females $(81.1 \%)$ and 79 males $(18.9 \%)$ with female:male ratio of 4.3:1 in that study. ${ }^{7}$ The latter study also found that the greatest prevalence of thyroid swelling is seen in pre-menopausal women. This also corroborates with our study where $70 \%$ cases (35 females) accounted for patients in the pre-menopausal age group of 16-45 years. Only 3 females in our study were outside this age group in the post-menopausal age and none were below the age of 16 years. Other authors have also concluded that thyroid swelling can develop in any age group but thyroid swellings are mostly seen between 21 to 40 years of age. ${ }^{8}$

In our study, the clinical diagnosis showed that diffuse goiter was found in $3(6 \%)$ patients, solitary thyroid nodule in $17(34 \%)$ patients and multinodular swelling was found in $30(60 \%)$ patients. Multinodular goiter was also the commonest clinical presentation followed by solitary thyroid nodule in the large case series already mentioned above. $^{7}$

The current study showed that colloid goiter was the commonest finding by FNAC among 41 patients (82\%), Hashimoto's thyroiditis was found among $6 \%$ patients, Langerhans cell Histiocytosis was found among 2\% patient, suspicious follicular neoplasm was found among 


\begin{tabular}{|c|c|c|c|}
\hline \multicolumn{2}{|c|}{ Final diagnosis } & \multirow{2}{*}{$\begin{array}{c}\text { Frequency } \\
1\end{array}$} & \multirow{2}{*}{$\begin{array}{c}\text { Percentage } \\
2 \%\end{array}$} \\
\hline Medically & Puberty goitre & & \\
\hline $\begin{array}{l}\text { managed } \\
\text { (4 cases) }\end{array}$ & Hashimoto's thyroiditis & 3 & $6 \%$ \\
\hline Surgically & Colloid goitre & 38 & $76 \%$ \\
\hline managed & Papillary carcinoma & 5 & $10 \%$ \\
\hline \multirow[t]{3}{*}{ (46 cases) } & $\begin{array}{l}\text { Langerhans cell } \\
\text { Histiocytosis }\end{array}$ & 1 & $2 \%$ \\
\hline & Follicular adenoma & 1 & $2 \%$ \\
\hline & Follicular carcinoma & 1 & $2 \%$ \\
\hline Total & & 50 & 100 \\
\hline
\end{tabular}

In 2 cases where preoperative FNAC was suggestive of colloid goiter, a hemithyroidectomy was initially done. But after histopathology report confirmed the diagnosis of underlying papillary carcinoma, the patients were counseled regarding the need to undergo completion thyroidectomy at a later date

$4 \%$ patients and papillary carcinoma was found among $6 \%$ patients. In a study by Rout et al, FNAC results showed that colloid goiter was also the most common among thyroid swelling $(42.2 \%)$ followed by thyroglossal cyst $(19.7 \%)$, colloid goiter with cystic degeneration $(13.2 \%)$, Hashimoto's thyroiditis $(10.6 \%)$, follicular adenoma $(7.8 \%)$ and papillary carcinoma (6.5\%). ${ }^{9}$ According to another study also, multinodular goiter was the most common non-neoplastic lesion and papillary carcinoma was the most common neoplastic lesion. ${ }^{4}$

In the current study, the most common operation performed was hemithyroidectomy in 31 out of 46 cases $(67.4 \%)$ followed by subtotal thyroidectomy and total thyroidectomy in 5 cases each $(10.8 \%$ each) etc. However, in the study by Aytac and Karamercan, subtotal thyroidectomy was the most commonly performed operation in 286 cases $(68.4 \%){ }^{7}$

FNAC was accurate in all except 4 cases in our study. The final histopathology report showed a different diagnosis in 2 cases (4\%) which came out to be papillary carcinoma but were suggestive of colloid goitre by FNAC in preoperative stage. The limitation of FNAC in diagnosis of follicular neoplasm is also well established. The 2 cases (4\%) of follicular neoplasm identified pre-operatively by FNAC came out to be one case each of follicular adenoma and follicular carcinoma on histopathology. In spite of its shortcomings, FNAC has an important role in evaluation of patients with thyroid swellings. According to Borgohain et al, ${ }^{10} \mathrm{FNAC}$ is a simple, safe and cost-effective diagnostic modality. The procedure has a central role in the management of thyroid nodules and should be used as the initial diagnostic test. According to them, a benign or inconclusive FNAC result should be viewed with caution as false negative results do occur and these patients should be followed up and any clinical suspicion of malignancy even in the presence of benign FNAC requires surgery. So, final diagnosis and treatment pattern should be based upon histopathology. ${ }^{10}$
Final histopathological analysis of the surgical specimens showed that $76 \%$ cases had features suggestive of colloid goitre. $14 \%$ of total cases consisted of thyroid neoplasms of which papillary carcinoma was most common $(10 \%)$ along with 1 case each (2\% each) of follicular adenoma and follicular carcinoma. In another study performed by Gupta et $\mathrm{al}^{11}$ in Jammu, India, the histopathological examination of excised specimens showed $42(56 \%)$ cases as colloid nodular goitre which is less than our figure. Other pathologies found in that study included 12 cases (16\%) of follicular adenoma, 12 cases $(16 \%)$ of papillary carcinoma, 3 cases $(4 \%)$ of Hurthle cell adenoma etc.

\section{CONCLUSION}

Females outnumbered males in a ratio of 3.16:1 in our study and maximum number of patients presented in 3645 years age group (42\%). Women in the pre-menopausal age group of 16-45 years comprised of $70 \%$ of total cases. Commonest clinical presentation was multinodular goitre $(60 \%)$ followed by solitary thyroid nodule $(34 \%)$ and diffuse goitre $(6 \%)$. Colloid goitre was most common pre-operative finding (82\%). 92\% cases required surgery and most common operation performed was hemithyroidectomy $(67.4 \%)$. Final diagnosis showed that $86 \%$ cases had nonneoplastic lesions while $14 \%$ cases consisted of thyroid neoplasms of which papillary carcinoma was most common $(10 \%)$. FNAC has an important role in initial evaluation of patients with thyroid swelling but histopathological examination of specimen is the gold-standard investigation for arriving at a correct diagnosis.

\section{REFERENCES}

1. Halbhavi SN, Ganjigatti M, Kuntoji SB and Karikazi MA. Clinicopathological study of thyroid swellings in HSK hospital in Karnataka, India. International Surgery Journal [Internet]. Medip Academy. 2018;5(2):420. https://doi.org/10.18203/2349-2902.isj20180038

2. Amudhan J, Vijay A, Latha $\mathrm{G}$ and Anandan H. Clinicopathological Study on Multinodular Goiter: A Prospective Study. Int J Sci Stud. 2017;5(1):83-85.

3. Jawaid AM, Rahim UD, Memon AM, Magsi BP, Shaikh MS and Marfani SM. Presentation, management and outcome of surgery PF thyroid swellings by ENT \& Head and Neck Surgeons at Civil Hospital Karachi. J Liaquat Uni Med Health Sci. 2012;11(2): 71-75.

4. Unnikrishnan GA and Menon VU. Thyroid disorders in India: An epidemiological perspective. Indian J Endocrinol Metab. 2011; 15(2): S78-S81.

https://doi.org/10.4103/2230-8210.83329

5. Chetan VR, Veeresalingam B, Kumar MK, Durbesula PT and Rao PS. A study on the clinical manifestations and the incidence of benign and malignant tumors in a solitary thyroid nodule. Int $\mathrm{J}$ Res Med Sci 2013; 1:429-434.

https://doi.org/10.5455/2320-6012.ijrms20131123

6. Borsaikia K and Patar M. Clinicopathological Study of Thyroid 
swellings with Some Emphasis on Geographical and Community Distribution: A Hospital Based Analysis. Bengal Journal of Otolaryngology and Head Neck Surgery. 2016;24(2):74-79.

https://doi.org/10.47210/bjohns.2016.v24i2.80

7. Aytac $B$ and Karamercan $A$. Recurrent laryngeal nerve injury and preservation in thyroidectomy. Saudi Med J. 2005;26(11):17461749.

8. Venkatachalapathy TS, Sreeramulu PN and Maddineni RK. A Prospective Study of Clinical, Sonological, Pathological Evaluation of Thyroid Nodule. Journal of Thyroid Disorders \& Ther. 2012;1(2):109.

9. Rout K, Ray CS, Behera SK and Biswal R. A Comparative study of FNAC and Histopathology of Thyroid swellings. Indian J Otolaryngol Head Neck Surg. 2011;63(4):370-372.

https://doi.org/10.1007/s12070-011-0280-0

10. Borgohain R, Lal KR, Chatterjee $\mathrm{P}$, Brahma $\mathrm{N}$ and Khanna S. A Study of Cyto-Histological Correlation in the Diagnosis of Thyroid Swelling. IOSR-JDMS. 2014;13(11):46-49. https://doi.org/10.9790/0853-131144649

11. Gupta M, Gupta S, Gupta VB. Correlation of Fine Needle Aspiration Cytology with Histopathology in the Diagnosis of Solitary Thyroid Nodule. Journal of Thyroid Research. Volume 2010, Article ID 379051, 5 pages.

https://doi.org/10.4061/2010/379051

\section{Author's Contribution:}

MT- Concept and design of the study, reviewed the literature, manuscript preparation and critical revision of the manuscript; PC- Concept, collected data and review of literature and helped in preparing first draft of manuscript

\section{Work attributed to:}

Department of Otorhinolaryngology, Teerthanker Mahaveer University, Moradabad.

\section{Orcid ID}

Dr Mohini Tyagi- (D) https://orcid.org/0000-0002-2418-898X

Dr Probal Chatterji- id https://orcid.org/0000-0003-4839-0696

Source of Funding: None, Conflict of Interest: None. 